\title{
Explicação e Descrição no Behaviorismo Radical: Identidade ou Dicotomia?
}

\author{
Carolina Laurenti ${ }^{1}$ \\ Universidade Federal de São Carlos \\ Carlos Eduardo Lopes \\ Universidade Estadual de Maringá
}

\begin{abstract}
RESUMO - Este artigo examina uma inconsistência na proposta skinneriana com respeito às relações entre explicação e descrição. Em alguns momentos, Skinner identifica explicação e descrição, comprometendo-se com a máxima machiana “explicar é descrever". Em outros momentos, Skinner desvincula os termos, considerando a descrição uma etapa preliminar do empreendimento científico, que deve ser complementada pela explicação. Argumenta-se, aqui, a favor da identidade entre explicação e descrição no Behaviorismo Radical com base nas influências de Mach na filosofia da ciência skinneriana. Defende-se ainda que essas influências se dão via selecionismo-pragmatismo, e não empirismo-descritivismo, contrastando com interpretações tradicionais das relações entre Mach e Skinner. Conclui-se que a identificação entre explicação e descrição parece expressar melhor as afinidades filosóficas do Behaviorismo Radical com o Pragmatismo.
\end{abstract}

Palavras-chave: Behaviorismo Radical; explicação; descrição; Ernst Mach; Pragmatismo.

\section{Explanation and Description in the Radical Behaviorism: Identity or Dichotomy?}

\begin{abstract}
This article examines an inconsistency in the Skinnerian proposal with respect to the relations between explanation and description. At some moments, Skinner identifies explanation and description, committing itself to the Machian principle "to explain is to describe". At other moments, Skinner detaches the terms, considering description as a preliminary stage of the scientific enterprise, which must be complemented by explanation. It is argued, here, in favor of the identity between explanation and description in the Radical Behaviorism on the basis of Mach influences in the Skinnerian philosophy of science. Moreover, it is stated that these influences take place through selectionism-pragmatism, and not empiricism-descriptivism. This analysis differs from traditional interpretations of the relations between Mach and Skinner. It is concluded that the identification between explanation and description seems to express better the philosophical affinities of Radical Behaviorism with Pragmatism.
\end{abstract}

Keywords: Radical Behaviorism; explanation; description; Ernst Mach; Pragmatism.

Nas últimas décadas, uma série de publicações tem discutido, de maneira calorosa, alguns pontos conflituosos do Behaviorismo Radical de B. F. Skinner (1904-1990). Esses debates, muitas vezes, giram em torno de algumas dicotomias bastante conhecidas na Filosofia: realismo versus instrumentalismo (Abib, 2003); realismo versus pragmatismo (Baum, 1994/1999; Tonneau, 2005); mecanicismo versus contextualismo (Carrara, 2004; Morris, 1988). Uma dessas dicotomias, que perpassa as discussões sobre a filosofia da ciência do comportamento skinneriana, é a díade descrição versus explicação.

Se, por um lado, alguns eminentes analistas do comportamento afirmam, quase de maneira banal, que explicar é descrever (Catania, 1998/1999), por outro lado, há autores que recomendam cautela em relação a essa afirmação (Marr, 2003). O objetivo deste ensaio é analisar a máxima "explicar

1 Endereço para correspondência: Departamento de Filosofia, Universidade Federal de São Carlos. Rodovia Washington Luís (SP-310), km 235. CEP 13565-905. São Carlos, SP. E-mail: carolinapsicologia@ hotmail.com. é descrever" a partir da influência de Ernst Mach (1838-1916) na filosofia da ciência do comportamento.

Esse objetivo justifica-se na medida em que é possível encontrar na obra skinneriana algumas incongruências em relação a esse assunto. Em um de seus primeiros artigos publicados, Skinner (1931/1961) parece não ter dúvida com respeito à identificação entre explicação e descrição:

Devemos adotar uma visão mais modesta de explicação e causalidade que parece ter sido primeiramente sugerida por Mach e é agora uma característica comum do pensamento cientifico, em que, em uma palavra, explicação é reduzida à descrição e a noção de causalidade é substituída pela de função. (pp. 337-338)

No entanto, no decorrer de sua obra, Skinner (1953) parece hesitar cada vez mais em relação a essa identidade. Mesmo reiterando algumas noções da filosofia da ciência machiana (como a substituição da conexão causal pela relação funcional, e dos termos 'causa' e 'efeito' por mudanças nas variáveis independentes e dependentes, respectivamente), 
Skinner declara que "a ciência é mais do que a mera descrição de eventos à medida que ocorrem. É uma tentativa de descobrir ordem, de mostrar que certos eventos mantêm relações ordenadas (lawful) com outros eventos" (p. 06).

Por fim, Skinner (1957) desvincula completamente 'explicação' de 'descrição', e define os termos como diferentes etapas no estudo do comportamento. O termo 'descrição' passa a ser reservado ao relato da topografia do comportamento. Já 'explicação' insere-se como um complemento da descrição, mediante a identificação das variáveis das quais o comportamento é função:

Nossa primeira responsabilidade é a simples descrição: qual é a topografia dessa subdivisão do comportamento humano? Uma vez que essa questão tenha sido respondida, pelo menos de uma maneira preliminar, podemos avançar para o estágio chamado explicação: quais condições são relevantes para a ocorrência do comportamento - quais são as variáveis das quais ele é uma função? (Skinner, 1957, p. 10)

Como entender essa incongruência no texto skinneriano? Partindo das recorrentes afirmações, tanto de estudiosos da obra skinneriana (Baum, 1994/1999; Chiesa, 1994; Smith, 1986), quanto do próprio Skinner (1931/1961, 1989), acerca da influência de Mach no Behaviorismo Radical, podemos perguntar em que medida a distinção fundamental entre explicação e descrição é legítima. Isso porque a identificação desses termos é uma característica marcante da filosofia da ciência machiana² (Chiesa, 1994; Mach, 1893/1960).

É justamente na tentativa de oferecer uma interpretação da relação explicação-descrição na obra skinneriana que se insere o presente ensaio. Defende-se, aqui, que a desvinculação entre 'explicação' e 'descrição' proposta por Skinner (1957) consiste em um afastamento momentâneo de Mach. Nesse sentido, compartilhamos da interpretação usual de que a filosofia da ciência skinneriana é mais bem analisada sob a ótica da influência machiana (Baum, 1994/1999; Chiesa, 1994).

Assim sendo, apresentaremos, inicialmente, uma breve discussão de duas interpretações da filosofia da ciência machiana: uma empirista-descritivista ${ }^{3}$ e outra selecionistapragmatista. É sob a perspectiva desse "segundo Mach" (selecionista-pragmatista) que examinaremos a máxima "explicar é descrever". Em seguida, analisaremos como

2 Convém destacar que, em um primeiro momento, Mach (1893/1960) criticou o conceito de explicação por considerá-lo comprometido com uma ontologia realista e com uma concepção causal mecanicista da natureza. No contexto dessa crítica, Mach destaca que a ciência deve descrever os fenômenos, isto é, o objetivo da ciência é estabelecer relações de dependência funcional entre os eventos na natureza. Quando a ciência cumpre esse objetivo, ela explica o fenômeno. Nesse sentido, Mach começa empregando o conceito de descrição para elucidar o conceito de explicação, e acaba redefinindo o conceito de explicação em termos de descrição. Em suma, segundo Mach, explica-se quando se descreve, e não quando se invoca elos inobserváveis para ajustar os eventos numa cadeia causal mecanicista, tal como concebe a explicação causal-realista de ciência.

3 O termo 'descritivista', conjugado com 'empirismo', é empregado aqui para expressar uma concepção filosófica de teoria científica que defende a redução da teoria a enunciados sobre dados observáveis (sense data) (Nagel, 1961). essa interpretação possibilita a desconstrução de uma série de dicotomias correlatas à díade explicação versus descrição (essência versus aparência, verdade versus falsidade, teoria versus observação e previsão versus descrição) tanto na obra de Mach quanto na de Skinner. Por fim, examinaremos a proposta de desidentificação dos termos operada por Skinner à luz dessa discussão prévia.

\section{Empirismo Descritivista ou Selecionismo Pragmatista: Delimitando a Perspectiva de Análise}

Uma das dificuldades em estabelecer relações entre a filosofia machiana e o Behaviorismo Radical é a existência de várias interpretações da obra de Mach (Banks, 2003; Cohen, 1970; Nagel, 1961). No interior dessa gama de interpretações há, pelo menos, duas leituras dos compromissos filosóficos de Mach: uma empirista-descritivista, e outra selecionistapragmatista.

A leitura empirista-descritivista, mais comum, defende que os principais conceitos e princípios machianos devem ser entendidos em relação à ênfase nos sense data ou dados da experiência (Nagel, 1961, pp. 117-129). Seguindo essa interpretação, a rejeição machiana da teoria atômica, por exemplo, deveria ser entendida sob a justificativa de que os átomos não podem ser observados; o mesmo valeria para a crítica do espaço absoluto newtoniano, que não pode ser verificado pelos sentidos (Banks, 2003). Na esteira dessa interpretação, o termo 'pseudoproblema' é entendido como um conjunto de proposições cuja validade não pode ser decidida empiricamente. Isso explicaria também a rejeição da metafísica, entendida como um conjunto de enunciados impossíveis de verificação empírica (Mach, 1886/1959). De maneira semelhante, o princípio de economia do pensamento é interpretado pela vertente empirista-descritivista como uma prescrição para reduzir os conceitos científicos aos sense data, facilitando a previsão e controle dos eventos da natureza (Banks, 2003).

Com isso, o viés empirista-descritivista acaba vinculando a filosofia de Mach ao Positivismo Lógico, considerando o físico austríaco como um precursor do posicionamento defendido pelo Círculo de Viena: "O pacote disso tudo nos dá uma figura do Mach 'positivista'. (...) Por razões históricas, então, é frequentemente conveniente ver a filosofia de Mach como uma versão inicial do empirismo do Círculo de Viena" (Banks, 2003, p. 3). Além disso, os próprios integrantes do Círculo de Viena consideram Mach como um dos seus mentores intelectuais (Banks, 2003).

No entanto, essa visão de um Mach arquipositivista vem sendo criticada por um movimento na filosofia da ciência, denominado "terceira onda", que nos últimos 30 anos tem questionado as afinidades entre Mach e o Círculo de Viena (Banks, 2003). Ao lado dessa crítica, surge uma faceta pouco explorada da filosofia da ciência de Mach, que enfatiza as influências do darwinismo, bem como elucida afinidades entre algumas noções machianas e o pragmatismo filosófico.

A vertente selecionista da filosofia de Mach aparece na sua proposta de uma epistemologia submetida à adaptação 
biológica (Mach, 1905/1976; Smith, 1986). Segundo essa acepção, a natureza do conhecimento deve ser tratada de três perspectivas: biológica, histórica e psicológica. Em sua perspectiva biológica, o conhecimento é analisado em termos de sua função em promover a sobrevivência do organismo. A perspectiva histórica conduz a duas investigações da evolução do conhecimento científico: uma que considera a gênese do conhecimento científico examinando as práticas primitivas dos ancestrais do homem; e outra que discute a constituição do conhecimento científico a partir do conhecimento ordinário (Mach, 1893/1960). Já a perspectiva psicológica da natureza do conhecimento envolve a análise de processos psicológicos (por exemplo, abstração, imaginação, adaptação do pensamento aos fatos) que participam da experiência de um sujeito (Mach, 1905/1976).

Dessa forma, seguindo uma concepção selecionista, o conhecimento científico é produto da interação: (1) de elementos da história biológica do cientista (enquanto membro de uma espécie dotada de processos que foram selecionados por assegurarem a sobrevivência); (2) de um processo evolutivo de práticas humanas; e (3) da experiência do pesquisador com o seu mundo.

Na esteira dessa análise, conhecimento é visto como uma "experiência mental direta ou indiretamente benéfica a nós" (Mach, 1905/1976, p. 84), ao passo que erro é concebido como uma experiência que impõe "consequências dolorosas" (p. 81). O próprio pensamento científico é eficiente porque é bem-sucedido em adaptar o homem ao seu ambiente. A observação passa a ser definida como a adaptação do pensamento aos fatos; a teoria, como a adaptação do pensamento a outros pensamentos.

No contexto dessa epistemologia selecionista, a vertente pragmatista de Mach (1905/1976) destaca-se. Na pesquisa científica, os conceitos e hipóteses são tratados como ferramentas intelectuais, cuja validade deve ser medida por sua utilidade em conduzir o pesquisador na realização de seus objetivos. As leis são vistas como descrições econômicas, mais especificamente, como receituários para uma ação científica bem-sucedida. A própria base empírica, sobre a qual são aferidos os enunciados da ciência, é historicamente contextualizada. Mesmo a escolha das leis gerais, sob as quais são subsumidas leis mais específicas para propósitos de explicação, é condicionada histórica e instintivamente. A noção de economia do pensamento, sob a ótica selecionistapragmatista, é interpretada como uma prescrição para tornar mais eficiente a relação do homem com a natureza, a partir do desenvolvimento de sistemas mais poderosos de informação e predição (Cohen, 1970).

A questão que resta é: o Mach selecionista-pragmatista é consistente com o Mach empirista-descritivista? Ao que parece, não. Esses dois "Machs" não são conciliáveis: "o sensacionalismo de Mach é austero, enquanto que seu evolucionismo é prolífico" (Cohen, 1970, p. 145). Neste ensaio examinaremos a máxima machiana "explicar é descrever" sob a ótica do Mach selecionista-pragmatista. Talvez essa perspectiva seja promissora para estabelecermos algumas relações entre Mach e Skinner, já que a filosofia da ciência skinneriana mostra afinidades tanto com o selecionismo (Skinner, 1981/1984), quanto com o pragmatismo (Skinner, 1974/1976).

\section{A Dissolução da Dicotomia "Explicação versus Descrição"}

A hipótese que perseguiremos aqui é que o sentido da máxima machiana "explicar é descrever", em uma interpretação selecionista-pragmatista, pode ser captado no contexto da dissolução de dicotomias correlatas à explicação versus descrição. Tais dicotomias são: essência versus aparência, verdade versus falsidade, teoria versus observação e previsão versus descrição.

\section{Essência versus aparência}

Uma das maneiras tradicionais de encaminhar a discussão das relações entre explicação e descrição insere-se no contexto de uma ontologia realista - aquela que se compromete com a existência de uma realidade em si. Uma das características marcantes do realismo é a dicotomia entre essência e aparência. No que concerne às relações entre explicação e descrição, teríamos a descrição ocupando-se da aparência das coisas, e a explicação de sua essência. Nesse sentido, 'descrição' nos remete para o campo dos fenômenos, daquilo que a experiência nos proporciona, do que é mutável, particular, perecível e contingente. Por outro lado, 'explicação' seria o processo de desvelamento do real, que visa entender o mundo como ele realmente é. Trata-se, pois, do que é imutável, universal, absoluto e necessário ${ }^{4}$.

Mach (1886/1959) não compactua com a dicotomia explicação versus descrição, na medida em que dissolve a dicotomia fundamental 'aparência-essência' ou 'aparênciarealidade'. Isso aparece de maneira evidente no exame machiano do fenômeno da refração. Quando mergulhamos um lápis na água, tendemos a dizer que ele parece curvo, mas na realidade é reto. O que justifica afirmar que, em uma situação, temos a realidade e, em outra, mera aparência? Mach afirma que, em ambos os casos, lidamos com relações de dependência entre eventos. A questão é que quando o lápis está submerso temos uma relação de dependência entre eventos distinta da ocasião em que o lápis está fora d'água: em um caso, a relação torna o lápis submerso oticamente curvado; em outro, torna-o tátil e metricamente reto. Nas palavras de Mach: "em ambos os casos temos que lidar com os fatos que se apresentam a nós com diferentes combinações de elementos, combinações que nos dois casos são condicionadas de modo diferente" (Mach, 1886/1959, p. 10).

Mas por que tendemos a considerar uma experiência real e outra ilusória? De acordo com Mach (1886/1959), quando não prestamos a devida atenção ao fato de que estamos tratando com duas combinações distintas de elementos,

4 A relação entre explicação e essência pode ser encontrada já em alguns pré-socráticos (como, por exemplo, Tales, Anaxágoras, Pitágoras, Parmênides), que buscavam estabelecer uma cosmologia por meio de princípios ou fundamentos ordenadores. Nesse sentido, para esses autores, a ordem seria a maneira adequada de compreender e explicar a natureza. Posteriormente, Platão (tradução. 1972) critica Anaxágoras, justamente por não levar adiante a proposta de explicar as coisas em termos do Espírito - um princípio ordenador e iniciador de tudo. Platão substitui, então, o Espírito pelas Formas ou Ideias (essências), que compõem um mundo imutável, absoluto e, por isso, real. 
caímos no erro natural de esperar aquilo que estamos mais acostumados a ver, no caso, o lápis reto. Em outro exemplo mais insólito, Mach dissolve a diferença entre mundo real e sonho, sugerindo que a "realidade" tem um caráter prático: "mesmo o sonho mais insensato (wildest) é um fato como qualquer outro. Se nossos sonhos fossem mais regulares, mais conectados, mais estáveis, eles também teriam mais importância prática para nós" (p. 11).

Em suma, a diferença entre essência e aparência, realidade (vigília) e sonho, não deve ser entendida como uma diferença de natureza: uma superior, que é a realidade, e outra inferior, que é mera aparência. Combinações distintas de elementos produzem experiências distintas. O que chamamos de realidade desponta, na perspectiva machiana, como uma experiência que tem maior utilidade prática para fins de sobrevivência, e não como algo transcendente que se define por relações absolutas e imutáveis. Da mesma forma, o que chamamos de aparência não tem um estatuto ontológico inferior; trata-se de uma experiência incomum quando comparada à experiência da "realidade".

Enquanto Mach (1886/1959) trata a diferença entre aparência e realidade como uma diferença na combinação dos elementos da natureza, Skinner (1953, 1974/1976) entende essa diferença em termos de relações distintas entre organismo e ambiente. Mais especificamente, o controle de estímulos está na base da diferença entre o que designamos por "aparência" e "realidade". Nas palavras de Skinner (1953): “posso 'pensar' que um objeto no céu é plano, e ver logo depois que é uma ave em pleno voo" (p. 138). O objeto plano não é mera aparência, e a ave a realidade: "as discrepâncias não estão na correspondência entre experiência e realidade, mas no controle de estímulos" (Skinner, 1974/1976, p. 89). O que está em jogo, aqui, são relações distintas entre organismo e ambiente; e não aparência, em um caso, e realidade, em outro.

Com efeito, via dissolução da diferença fundamental entre essência e aparência, Skinner (1953, 1974/1976) parece não se comprometer com a dicotomia explicação versus descrição. Por essa razão, pode-se dizer, inicialmente, que explicar, no Behaviorismo Radical, é descrever relações entre organismo e ambiente. Dependendo de como se dão essas relações, tendemos a designá-las como "aparência" ou como "realidade".

\section{Verdade versus falsidade}

Outro aspecto que parece afastar Mach (1905/1976) da dicotomia explicação versus descrição é sua crítica da concepção realista de verdade. Em uma perspectiva realista, verdade combina com realidade; verdade é correspondência com uma realidade imutável. Seguindo essa concepção, explicar é descobrir a verdade, a realidade que está atrás do fenômeno (aparência). Nesse sentido, a descrição sempre é incerta ou imprecisa, pois lida apenas com a aparência das coisas (com as regularidades contingentes entre eventos).

Mach (1905/1976) não se compromete com as dicotomias certeza-incerteza e verdade-falsidade, características do realismo. Esse afastamento se reflete já no emprego dos termos 'conhecimento' e 'erro', ao invés da díade 'verdadefalsidade'. Diferente da concepção realista, subjacente aos conceitos de verdade e falsidade, conhecimento e erro são de uma mesma natureza. Isso quer dizer que os mesmos processos (adaptação do pensamento aos fatos, adaptação do pensamento a outros pensamentos, abstração) estão na gênese tanto do conhecimento, quanto do erro: "conhecimento e erro fluem da mesma fonte mental, somente o sucesso pode diferenciar um do outro" (Mach, 1905/1976, p. 84).

A despeito de compartilharem da mesma natureza, conhecimento e erro diferem entre si com base na efetividade. De modo geral, Mach (1905/1976) define conhecimento como ações e regras bem-sucedidas para alcançar certos objetivos teóricos e práticos, e erro por ações e regras ineficazes. No âmbito da ciência, o erro acontece quando o cientista negligencia diferenças significativas entre fenômenos. Quando, por exemplo, faz generalizações indevidas, desconsiderando mudanças de contextos: "o erro sobrevém somente quando consideramos que um fato ainda continua a existir sob outras circunstâncias e ignoramos a mudança nas circunstâncias, física, mental ou ambas" (p. 84)

Dessa forma, outra importante consequência do afastamento de Mach (1905/1976) da dicotomia verdade versus falsidade é o abandono do conceito de verdade como correspondência com uma realidade em si, e a adoção do conceito de verdade como efetividade. Esse posicionamento aproxima Mach do pragmatismo filosófico de William James (18421910), principalmente no que concerne ao conceito pragmático de verdade defendido pelo filósofo norte-americano: "qualquer ideia que nos transporte prosperamente de qualquer parte de nossa experiência para qualquer outra parte, ligando as coisas satisfatoriamente, trabalhando seguramente, simplificando, economizando trabalho; é verdadeira por tudo isso, verdadeira em toda extensão, verdadeira instrumentalmente" (James, 1963/1967, p. 50).

Em suma, a dicotomia verdade versus falsidade é abandonada por Mach (1905/1976) por estar fundamentada em uma ontologia realista, incompatível com os compromissos filosóficos do físico austríaco. Com a crítica ao realismo, Mach defende verdade como efetividade (conhecimento), e falsidade como ineficácia (erro).

Tal como Mach (1905/1976), Skinner (1974/1976) parece comprometer-se com uma concepção pragmatista de verdade, aferindo a verdade de uma teoria em termos das consequências efetivas que produz, e a sua falsidade em termos de consequências danosas. Skinner (1974/1976) ecoa a afirmação pragmatista de verdade como efetividade, quando declara: "uma proposição é 'verdadeira' na medida em que ajuda o ouvinte responder efetivamente a situações que ela

5 Vale ressaltar que, para Mach (1886/1959), o que diferencia físico de mental é apenas a perspectiva de análise e não a natureza do evento: "assim, o grande abismo entre a investigação física e a psicológica persiste apenas quando nos apegamos a nossas concepções estereotipadas habituais. (...) Não é o objeto de estudo, mas a direção de nossa investigação que é diferente nos dois domínios [físico e psicológico]" (pp. 17-18). Com isso, Mach adota uma perspectiva relacional de conhecimento, na qual sujeito e objeto constituem-se $n a$ relação cognitiva. Consequentemente, quando Mach aponta as generalizações indevidas como uma das fontes de erro, isso não pode ser entendido nem de modo realista (o que priorizaria o físico), nem de modo idealista (o que priorizaria o mental). 
descreve" (p. 259). Ou ainda: "há um sentido especial em que ele [o conhecimento científico] poderia ser 'verdadeiro', se ele produzisse a ação mais eficaz possível” (p. 259).

Para o Behaviorismo Radical, uma teoria, proposição, ou conceito são verdadeiros se produzirem consequências efetivas para quem os formula. Nesse sentido, o empreendimento científico não tem como objetivo o desvelamento do real, da essência das coisas, mas a produção de consequências efetivas. De maneira semelhante, uma teoria, proposição, ou conceito são considerados falsos quando não produzem consequências efetivas.

Considerando que essas definições de 'verdade' e 'falsidade' estão circunscritas em uma visão selecionista, temos uma relação dinâmica entre verdade e falsidade: teorias, proposições e conceitos verdadeiros (efetivos na produção de certas consequências) são adotados (selecionados), enquanto que teorias, proposições e conceitos falsos (ineficazes na produção de certas consequências) são abandonados. Evidentemente, a adoção ou rejeição de certas teorias está condicionada ao contexto histórico do cientista; como esse contexto é mutável, não há uma teoria definitivamente verdadeira ou definitivamente falsa. A verdade ou falsidade é sempre provisória:

A verdade de um enunciado de fato é limitada pelas fontes do comportamento do falante, pelo controle exercido pelo cenário atual, pelos efeitos de cenários semelhantes no passado, e pelos efeitos sobre o ouvinte, que conduzem à precisão ou ao exagero, ou à falsificação, e assim por diante. Não há como uma descrição verbal de um cenário ser absolutamente verdadeira. (Skinner, 1974/1976, p. 150)

Desse modo, a visão tradicional de que uma explicação verdadeira se define pelo desvelamento da essência das coisas, e de que a descrição, por restringir-se ao plano das aparências, não pode assegurar a verdade, não parece ser adequada para expressar a filosofia da ciência skinneriana. Explicar é descrever relações funcionais entre organismo e ambiente. E essas descrições serão acolhidas no corpo teórico da ciência skinneriana conforme as consequências que produzirem para a compreensão, previsão e controle do comportamento. Com efeito, explicar, na perspectiva skinneriana, é descrever relações "verdadeiras" entre organismo e ambiente, isto é, descrever relações entre organismo e ambiente que produzem consequências efetivas.

\section{Teoria versus observação}

A dicotomia teoria versus observação muitas vezes é encarada como uma contraparte exata da dicotomia explicação versus descrição. Nesse contexto, descrever é simplesmente contar aquilo que se passa diante de nossos olhos. Em uma acepção científica, descrever é relatar fatos observáveis, o que aparentemente não parece exigir muita participação daquele que descreve. Descrever é quase como ver. Já a explicação requer, no mínimo, uma organização de fatos observáveis. É mais que descrever ou ver; é ir além dos próprios fatos. É contribuir com algo de si mesmo, é interpretar (Hanson, 1975).
Mais uma vez, Mach (1905/1976) rompe com a dicotomia descrição versus explicação não aceitando seu correlato: observação versus teoria. É o próprio Mach quem declara: "observação e teoria não estão nitidamente separadas, uma vez que qualquer observação já está influenciada por uma teoria, e essa observação, por sua vez, reage sobre a teoria" (p. 120).

Nesse contexto, o preceito machiano "explicar é descrever" não pressupõe a "passividade" defendida pela teoria empirista da descrição, para a qual 'descrever' é simplesmente 'ver'. Explicamos quando descrevemos e, no ato de descrever, a experiência do cientista desempenha um papel "ativo" na produção do conhecimento:

\begin{abstract}
Simplesmente averiguar os fatos com precisão e representálos no pensamento requer mais iniciativa do que é comumente suposto. Para que se seja capaz de dizer que um elemento depende de outro e como isso se dá (segundo a noção de relação funcional), um pesquisador deve contribuir com algo de si próprio além do que é imediatamente observado. Seria um erro pensar que alguém pode depreciar isto por chamá-lo de descrição. (Mach, 1905/1976, p. 234)
\end{abstract}

A passagem deixa claro que descrever já é interpretar. Nesse sentido, a dissolução machiana da dicotomia teoria versus observação vai contra algumas suposições características do empirismo, como as noções de observação pura e dados brutos, que afirmam a possibilidade de uma observação ou descrição neutra, independente de pressuposições teóricas. Com isso, leituras estritamente empiristas da filosofia da ciência machiana tornam-se suspeitas.

Skinner (1953) parece também compartilhar da crítica ao empirismo em, pelo menos, dois momentos. Em primeiro lugar, quando não aceita a distinção fundamental entre ver e interpretar: “"ver' é o comportamento 'interpretativo' que um estímulo controla" (p. 140). Se 'ver' já é interpretar, a defesa do itinerário empirista (primeiro vemos/descrevemos e depois interpretamos/explicamos) torna-se inviável ${ }^{6}$.

Em segundo lugar, a incompatibilidade com o empirismo surge quando Skinner (1969) defende uma função "construtiva" das teorias. O conceito de contingência de reforço expressa bem esse papel ativo da teoria. A partir desse conceito, Skinner afirma que "já não olhamos (look at) mais comportamento e ambiente como coisas ou eventos separados, mas as inter-relações entre eles. Vemos (look at) as contingências de reforço" (p 10). Isso significa que, por meio do conceito de contingência de reforço, nós "vemos" as

6 No entanto, é preciso apontar que o posicionamento de Skinner (1953) em relação a esse assunto não é inequívoco. No próprio Science and Human Behavior é possível encontrar usos do termo 'descrever' próximos do sentido empirista de "simplesmente ver": "a ciência é mais que mera descrição de eventos à medida que ocorrem. É uma tentativa de descobrir ordem, de mostrar que certos eventos mantêm relações ordenadas com outros eventos" (p. 6). Estamos interessados neste ensaio em encontrar apoio para uma interpretação pragmatista das relações entre explicar e descrever no Behaviorismo Radical. No entanto, adotamos uma noção de interpretação que não exclui a possibilidade de outras interpretações. O critério de escolha por uma dentre as possíveis interpretações é também pragmático, ou seja, pautado pelas consequências produzidas na prática do analista do comportamento ao adotar uma dada interpretação. 
relações funcionais entre organismo e ambiente. Nessa linha de raciocínio, podemos dizer que o operante, por exemplo, só é um fato no contexto teórico-conceitual da Análise do Comportamento. Em outras palavras, o operante não é um fato em si mesmo, independente da própria teoria operante. Com isso, a teoria tem a função de dirigir o olhar do analista do comportamento construindo os dados de sua ciência.

Assim, para o Behaviorismo Radical, não há um fato "duro", puro, objetivo em si mesmo. Mudanças nos sistemas teóricos envolvem mudanças nos próprios fatos; e mudanças nos fatos impõem, por sua vez, novos desafios à teoria científica. Isso nos conduz à conclusão de que uma demarcação absoluta entre observação e teoria não parece possível. Consequentemente, torna-se inviável defender uma separação absoluta entre descrição e explicação no behaviorismo skinneriano.

Em suma, contrariando interpretações tradicionais do Behaviorismo Radical (Marx \& Hillix, 1963/1978), parece possível uma leitura dessa filosofia que a desvincula de um modelo empirista de ciência. Enquanto o empirismo defende a neutralidade dos dados empíricos (descrição), e atribui as diferenças nos relatos científicos às diferenças nas interpretações dos cientistas (explicação), a presente proposta argumenta que descrever, no Behaviorismo Radical, é interpretar relações entre organismo e ambiente.

\section{Previsão versus descrição}

Mach (1905/1976) também dissolve a dicotomia explicação versus descrição colapsando a dicotomia previsão versus descrição. Tradicionalmente se diz que a descrição é limitada, pois não permite previsão. Se 'descrição' é vista como um resumo ou compêndio de fatos observáveis, tal como defende a vertente empirista, ela restringe-se apenas ao relato da experiência. Por outro lado, uma das condições para que uma dada explicação seja considerada satisfatória é, justamente, a possibilidade de ela mostrar que, mediante a realização de certas condições antecedentes, podemos esperar a ocorrência do fato a ser explicado (Nagel, 1961).

Quando Mach (1905/1976) examina o papel das leis e dos conceitos científicos, deixa claro que a descrição não é simplesmente um registro condensado de experiências. Na perspectiva machiana, as leis não são um mero relato de fatos que já ocorreram, mas são prescrições condicionais da experiência (Cohen, 1970). Isso significa que a realização de condições especificadas em uma lei torna possível a formulação de enunciados descritivos sobre a ocorrência de novos eventos. Sobre esse assunto, Cohen afirma que a filosofia da ciência de Mach "alarga a extensão da 'descrição’. Leis vão além da experiência dada; leis não funcionam somente como descrições, mas também como prescrições para descrições (...). Assim, leis são descrições condensadas e estendidas" (p. 137).

Em relação aos conceitos, Mach (1905/1976) afasta-se novamente dos empiristas quando defende que os conceitos não são simplesmente um resumo de fatos observáveis, mas guias que orientam o pesquisador na descoberta de fatos futuros. Nas palavras de Mach: "O propósito dos conceitos é permitir encontrar nosso caminho no emaranhado confuso dos fatos" (p. 98).
Outra característica marcante do tratamento dado por Mach (1905/1976) aos conceitos é a crítica às hipóstases e reificações na ciência. Na perspectiva machiana, os conceitos têm um papel exclusivamente instrumental na investigação dos eventos da natureza. Esse instrumentalismo justifica a polêmica posição de Mach em relação à teoria atômica: "usar conceitos não faria a ciência física ver em suas moléculas e átomos - ferramentas econômicas, autocriadas, mutáveis - realidades atrás do fenômeno (...). O átomo deve permanecer uma ferramenta para representar o fenômeno, como as funções da matemática” (Mach, 1894/1943, pp. 206-207, grifos nossos).

Se, por um lado, o tratamento peculiar dos conceitos afasta Mach do empirismo, por outro, parece aproximálo do pragmatismo instrumentalista de John Dewey (1859-1952):

Um empirismo que está satisfeito com a repetição de fatos já
passados não tem lugar para possibilidade e para liberdade.
Ele não pode achar espaço para concepções ou ideias gerais,
pelo menos um espaço que não ultrapasse a função de meros
resumos ou registros. Mas quando adotamos o ponto de vista
do pragmatismo vemos que ideias têm uma função diferente a
desempenhar do que aquela de relatar e registrar experiências
passadas. Elas são as bases para organizar observações e
experiências futuras. (Dewey, 1922/1981, p. 50)

Com efeito, ao enunciar que "explicar é descrever", Mach (1905/1976) não identifica descrição com o mero registro de experiências passadas. Em Mach, tal como no pragmatismo deweyano, a formulação de leis e conceitos possibilita que experiências futuras sejam organizadas de acordo com uma estrutura conceitual. Essa "acomodação" de experiências futuras pode, em última instância, ser expressa na forma de previsões. Em suma, descrição é compatível com previsão.

No caso do Behaviorismo Radical, a dissolução da dicotomia previsão versus descrição também fica evidente quando se examina o papel das leis na ciência do comportamento skinneriana. Em primeiro lugar, leis são descrições de contingências: "As leis da ciência descrevem contingências que prevalecem no ambiente completamente aparte de qualquer ação humana deliberada" (Skinner, 1974/1976, p. 138, grifo nosso).

Em segundo lugar, diferente da visão tradicional, que julga impossível a compatibilidade entre descrição e previsão, Skinner (1953) defende que as leis, enquanto descrições, podem permitir tanto a previsão quanto o controle do comportamento: "Ao arranjarmos as condições do modo especificado pelas leis de um sistema, não somente prevemos, nós controlamos: 'causamos' o evento, ou fazemos ele assumir certas características” (Skinner, 1953, p. 14). De imediato, podemos dizer que Skinner adota um conceito de lei científica que rompe com a dicotomia descrição versus previsão.

Em terceiro lugar, as leis funcionam como regras para uma ação científica bem-sucedida: "Ao aprender as leis da ciência, uma pessoa é capaz de comportar-se efetivamente sob contingências de um mundo extraordinariamente complexo" (Skinner, 1974/1976, p. 138). Como regras, as leis se destacam como uma maneira econômica do cientista adquirir comportamentos efetivos em contingências extremamente complexas. A princípio, esses comportamentos poderiam ser 
inteiramente modelados por contingências, isto é, aprendidos pela própria experiência do cientista. No entanto, dado a complexidade desses comportamentos, o processo de variação e seleção, responsável por sua instalação, poderia levar muito tempo, ou até mesmo nunca ocorrer.

Já com o emprego de leis, essa exigência temporal da modelagem por contingências pode ser evitada. Ao seguir leis, o cientista emite comportamentos efetivos em contingências complexas, sem a necessidade de modelagem prévia. Em outras palavras, ao seguir leis, os cientistas não precisam percorrer novamente todos os passos que levaram à formulação da lei:

A ciência a leva [a pessoa] para além de sua experiência pessoal e além da amostragem deficiente da natureza, que é inevitável no tempo de vida de uma pessoa. Ela também coloca a pessoa sob o controle de condições que não poderiam desempenhar qualquer papel na modelagem e manutenção de seu comportamento. (Skinner, 1974/1976, p. 138) ${ }^{7}$

Em suma, no contexto da discussão do papel desempenhado pelas leis científicas, a descrição mostra-se compatível com a previsão. As leis, entendidas como descrições de contingências, não se resumem ao mero registro da experiência passada. Isso fica ainda mais conspícuo, no caso de behaviorismo skinneriano, devido ao seu consequencialismo. A ênfase de Skinner (1974/1976) nas consequências da ação permite que a descrição não seja vista como um mero resumo de fatos já passados. A descrição, seja na forma de leis ou conceitos científicos, serve de base para organizar observações e experiências futuras. Ela projeta a experiência para o futuro, não apenas como a possibilidade de previsão dos eventos da natureza, mas como uma prescrição para uma ação científica bem-sucedida em situações complexas. Nesse caso, não parece ser contraditório afirmar que explicar é descrever relações entre organismo e ambiente que permitem a previsão de novos comportamentos.

\section{Considerações Finais}

A literatura filosófica indica a existência de, pelo menos, dois "Machs", um empirista-descritivista e um selecionistapragmatista (Banks, 2003; Cohen, 1970). Considerando os compromissos filosóficos do Behaviorismo Radical, parece que o "segundo Mach" apresenta-se como um interlocutor com melhores condições de estabelecer um diálogo virtuoso com Skinner. De uma perspectiva selecionista-pragmatista, a máxima machiana "explicar é descrever" adquire um sentido mais fecundo. Ela transgride as dicotomias comuns do discurso científico e filosófico. O seu significado é incompatível

7 Mencionamos, aqui, o papel desempenhado pelas regras na atividade científica. No entanto, é preciso ressaltar que, para o Behaviorismo Radical, comportamentos modelados por contingências participam de praticamente todas as etapas da produção de conhecimento na ciência (na identificação de problemas de pesquisa, no planejamento de experimentos, na interpretação e apresentação dos dados, e assim por diante). Dessa forma, o Behaviorismo Radical parece afastar-se de uma concepção de ciência moderna, em que a contribuição da experiência pessoal do cientista (comportamento modelado por contingências) deve ser evitada ao máximo. com a defesa de uma diferença fundamental entre essência e aparência, verdade e falsidade, teoria e observação, previsão e descrição. Com efeito, o sentido da máxima "explicar é descrever" parece ser captado justamente no contexto da dissolução dessas dicotomias.

No que concerne à relação entre explicação e descrição, também parece haver dois "Skinners". Um que se compromete com a identificação entre explicação e descrição; outro que desidentifica esses termos. Compreender essa inconsistência não é uma tarefa fácil. Por um lado, Skinner (1989) reconhece Mach como um fator decisivo para a constituição do Behaviorismo Radical: "Divergi tanto de Tolman quanto de Hull, por seguir uma linha estritamente machiana, na qual o comportamento era analisado como objeto de estudo em si mesmo, como uma função de variáveis ambientais, e sem referência à mente ou ao sistema nervoso" (pp. 110-111, grifos nossos).

Por outro lado, há enunciados que apontam para uma ruptura com a proposta machiana, como, por exemplo, os encontrados no Verbal Behavior que desvinculam 'explicação' de 'descrição', considerando descrição e explicação como etapas distintas do estudo do comportamento (Skinner, 1957, p. 10).

Há mais de uma maneira de interpretar essa inconsistência do texto skinneriano. Aqui, examinamos a querela entre explicação e descrição através dos compromissos filosóficos assumidos por Skinner. Propomos uma análise desses compromissos à luz de uma leitura selecionista-pragmatista de Mach. Tal como em Mach, a vertente selecionista-pragmatista de Skinner pode ser esclarecida no contexto da dissolução das dicotomias: essência-aparência, verdade-falsidade, teoria-observação e previsão-descrição. Defendemos, assim, a plausibilidade da identidade entre explicação e descrição, no Behaviorismo Radical, via selecionismo pragmatista.

Skinner (1953, 1974/1976) critica a diferença fundamental entre essência e aparência, verdade e falsidade, teoria e observação, previsão e descrição. Isso sugere que a dicotomia explicação versus descrição, que pertence a uma rede conceitual semelhante às primeiras dicotomias, não expressa de maneira adequada os compromissos filosóficos do Behaviorismo Radical. Com efeito, podemos dizer que explicar no Behaviorismo Radical é descrever (interpretar) relações entre organismo e ambiente que produzem consequências efetivas, que são compatíveis com a previsão do comportamento.

Tendo no horizonte as filiações filosóficas de Skinner, a desvinculação entre explicar e descrever, explicitamente anunciada no Verbal Behavior, é interpretada mais como um "ruído" no texto skinneriano, do que como uma possível evidência da maturidade da obra do autor.

Partindo de uma leitura selecionista-pragmatista da teoria da descrição machiana, as relações entre Mach e Skinner talvez ultrapassem os limites do empirismo descritivista, que tradicionalmente parece ser considerado uma "chave de leitura" para tecer essas relações (Chiesa, 1994). Se as afinidades entre Mach e Skinner podem ser ressaltadas por meio do selecionismo pragmatista, qual será a amplitude das relações entre esses autores? Presumivelmente, o diálogo entre Mach e Skinner deixa de ter como palco privilegiado apenas o início da obra do psicólogo norte-americano, para se estender aos textos que mostram afinidades com o pragmatismo filosófico. 
Considerando esse possível alargamento das relações entre Mach e Skinner, via selecionismo pragmatista, resta ainda a seguinte questão: por que Skinner (1957) desvincula 'explicação' de 'descrição' no Verbal Behavior? A questão torna-se ainda mais espinhosa se considerarmos que o livro de 1957 mostra notáveis afinidades com o contextualismo, uma versão do pragmatismo filosófico. Isso fica evidente, por exemplo, quando Skinner (1957) adota uma teoria funcional do significado, em lugar de uma teoria referencial do significado (Abib, 1994).

Sob a perspectiva da diferença fundamental entre explicar e descrever, o comportamento é descrito quando sua topografia é relatada, e explicado quando são identificadas as variáveis das quais é função (Skinner, 1957, p. 10). Mas, sob a ótica da identidade entre explicação e descrição, a dicotomia entre topografia e função parece ser uma falsa dicotomia. Talvez aqui tenhamos mais uma ampliação do sentido da máxima "explicar é descrever" no Behaviorismo Radical: explicar é descrever relações dinâmicas entre topografia e função.

\section{Referências}

Abib. J. A. D. (1994). O contextualismo do comportamento verbal: a teoria skinneriana do significado e sua crítica ao conceito de referência. Psicologia: Teoria e Pesquisa, 10, 473-487.

Abib, J. A. D. (2003). Behaviorismo radical e interpretação. Em M. Z. S. Brandão, F. C. Conte, F. S. Brandão, Y. H. Ingberman, C. B. Moura, V. M. Silva \& S. M. Oliane (Orgs.), Sobre comportamento e cognição: a história e os avanços, a seleção por conseqüencias em ação, Vol. 11 (pp. 57-65). Santo André: ESETec.

Banks, E. C. (2003). Ernst Mach's world elements: A study in natural philosophy. Dordrecht, Holland: Kluwer Academic Publishers.

Baum, W. (1999). Compreender o behaviorismo: ciência, comportamento e cultura (M. T. Araújo, M. A. Matos, G. Y. Tomanari \& E. Z. Tourinho, Trads.). Porto Alegre: Artmed. (Trabalho original publicado em 1994)

Catania, A. C. (1999). Aprendizagem: comportamento, linguagem e cognição (A. Schmidt, D. G. de Souza, F. C. Capovilla, J. C. C. de Rose, A. A. Costa, L. M. C. M. Machado \& A. Gadotti, Trads.). Porto Alegre: Artmed. (Trabalho original publicado em 1998)

Carrara, K. (2004). Causalidade, relações funcionais e contextualismo: algumas indagações a partir do Behaviorismo Radical. Interações, 9, 29-54.

Chiesa, M. (1994). Radical behaviorism: The philosophy and the science. Boston: Authors Cooperative.

Cohen, R. S. (1970). Physics, perception, and philosophy of science. Em R. S. Cohen \& R. J. Seeger (Orgs.), Ernst Mach: Physicist and philosopher (pp. 126-164). Dordrecht: D. Reidel.

Dewey, J. (1981). The development of American pragmatism. Em J. McDermott (Org.), The philosophy of John Dewey (pp. 4158). Chicago: The University of Chicago Press. (Originalmente publicado em 1922)

Hanson, N. R. (1975). Observação e interpretação (L. Hegenberg \& O. S. Da Mota, Trads.). Em S. Morgenbesser (Org.), Filosofia da ciência (pp. 127-138). São Paulo: Cultrix/EDUSP.
James, W. (1967). O que significa o pragmatismo (J. C. da Silva, Trad.). Em W. James (Org.), Pragmatismo e outros ensaios (pp. 43-61). Rio de Janeiro: Lidador. (Trabalho original publicado em 1963)

Mach, E. (1943). The economical nature of physical inquiry (T. J. McCormach, Trad.). Em E. Mach (Org.), Popular scientific lectures (pp. 186-213). Illinois: Open Court. (Trabalho original publicado em 1894)

Mach, E. (1959). The analysis of sensations (C. M. Williams, Trad.). New York: Dover Publications. (Trabalho original publicado em 1886)

Mach, E. (1960). The science of mechanics: A critical and historical account of its development (T. J. McCormack, Trad.). Illinois: Open Court. (Trabalho original publicado em 1893)

Mach, E. (1976). Knowledge and error: Sketches on the psychology of enquiry (P. Foulkes, Trad.). Boston: D. Reidel. (Trabalho original publicado em 1905)

Marr, M. J. (2003). The what, the how, and the why: The explanation of Ernst Mach. Behavior and Philosophy, 31, 181-192.

Marx, M. H., \& Hillix, W. A. (1978). Sistemas e teorias em psicologia (A. Cabral, Trad.). São Paulo: Cultrix. (Trabalho original publicado em 1963)

Morris, E. K. (1988). Contextualism: The world view of behavior analysis. Journal of Experimental Child Psychology, 46, 289323.

Nagel, E. (1961). The structure of science: Problems in the logic of scientific explanation. New York: Harcourt, Brace \& World.

Platão (trad. 1972). Fédon (J. Paleikat \& J. C. Costa, Trads.). Coleção Os Pensadores (pp. 61-132). São Paulo: Abril Cultural.

Skinner, B. F. (1953). Science and human behavior. New York: MacMillan.

Skinner, B. F. (1957). Verbal behavior. New Jersey: PrenticeHall.

Skinner, B. F. (1961). The concept of the reflex in the description of behavior. Em B. F. Skinner (Org.), Cumulative record: A selection of papers (pp. 319-346). New York: AppletonCentury-Crofts. (Originalmente publicado em 1931)

Skinner, B. F. (1969). Contingencies of reinforcement: A theoretical analysis. New York: Appleton-Century-Crofts.

Skinner, B. F. (1976). About behaviorism. New York: Vintage Books. (Originalmente publicado em 1974)

Skinner, B. F. (1984). Selection by consequences. The Behavioral and Brain Sciences, 7, 477-481. (Originalmente publicado em 1981)

Skinner, B. F. (1989). Recent issues in the analysis of behavior. Columbus: Merrill Publishing Company.

Smith, L. D. (1986). Behaviorism and logical positivism: A reassessment of the alliance. Stanford: Stanford University Press.

Tonneau, F. (2005). Antirealist arguments in behavior analysis. Behavior and Philosophy, 33, 55-65.

Recebido em 27.09.07

Primeira decisão editorial em 08.04.08

Versão final em 22.04.08

Aceito em 18.08 .08 